\title{
Primary Care Patient Experience with Naloxone Prescription
}

\author{
Emily Bebar, $M S^{1,2}$ \\ Cbristopher Rowe, MPH \\ Glenn-Milo Santos, PbD, MPH ${ }^{1,2}$ \\ Sheigla Murpby, $\mathrm{PbD}^{3}$ \\ Pbillip O. Coffin, MD, MIA ${ }^{1,2}$ \\ 'San Francisco Department of Public \\ Health, San Francisco, California \\ ${ }^{2}$ University of California San Francisco, \\ San Francisco, California \\ ${ }^{3}$ Institute for Scientific Analysis, San Fran- \\ cisco, California
}

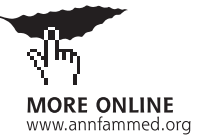

Conflicts of interest: Dr Coffin bas led studies that bave received donated medications from Alkermes and Gilead.

\section{CORRESPONDING AUTHOR}

Emily Behar, MS

San Francisco Department of Public Health 25 Van Ness Ave, Suite 500

San Francisco, CA 94102

Emily.behar@sfdph.org

\begin{abstract}
PURPOSE Notwithstanding a paucity of data, prescription of the opioid antagonist naloxone to patients prescribed opioids is increasingly recommended in opioid stewardship guidelines. The aim of this study was to evaluate chronic pain patients' attitudes toward being offered a naloxone prescription and their experience with naloxone.
\end{abstract}

METHODS We interviewed 60 patients who received naloxone prescriptions across 6 safety-net primary care clinics (10 patients per clinic) from October 2013 to October 2015. We used a standardized questionnaire to collect information on substance use, perception of personal overdose risk, history of overdose, and experiences with naloxone prescription, including initial reaction, barriers to filling the prescription, storage and use of naloxone, associated behavioral changes, and opinions about future prescribing.

RESULTS Respondents were demographically similar to all clinic patients receiving opioid prescriptions. Ninety percent had never previously received a naloxone prescription, $82 \%$ successfully filled a prescription for naloxone, and $97 \%$ believed that patients prescribed opioids for pain should be offered naloxone. Most patients had a positive (57\%) or neutral $(22 \%)$ response to being offered naloxone, and $37 \%$ reported beneficial behavior changes after receiving the prescription; there were no harmful behavior changes reported. Although $37 \%$ had personally experienced an opioid-poisoning event (17\% of which were described as bad reactions but consistent with an overdose) and 5\% reported that the prescribed naloxone had been used on them, $77 \%$ estimated their risk of overdose as low.

CONCLUSIONS Primary care patients on opioids reported that receiving a prescription for naloxone was acceptable, the prescription reached patients who had not had access to naloxone, and having naloxone may be associated with beneficial changes in opioid use behaviors. Patients prescribed opioids may not interpret the terminology describing overdose to imply unintentional opioid poisoning.

Ann Fam Med 2016;14:431-436. doi: 10.1370/afm.1972.

\section{INTRODUCTION}

$\mathrm{D}$ rug overdose, driven by opioids, is the leading cause of accidental death in the United States, accounting for more than 47,000 deaths in 2014. ${ }^{1}$ Distribution of the opioid antagonist naloxone has been associated with a reduction in opioid overdose mortality ${ }^{2,3}$ and is recommended for patients prescribed opioids with such risk factors as receipt of more than $50 \mathrm{mg}$ morphine equivalents, concurrent benzodiazepine use, or substance use disorder. ${ }^{4-6}$

Recommendations to prescribe naloxone from primary care settings are based on scarce data. Naloxone and overdose prevention education given to primary care patients in North Carolina was associated with a $40 \%$ decline in overdose mortality in an ecological analysis, ${ }^{7}$ and a program at US Army Fort Bragg reported a decline from 8 overdoses monthly to none after beginning naloxone prescribing. ${ }^{8}$ Clinicians have noted several potential barriers to prescribing naloxone, including lack of training 
and fear of offending patients ${ }^{9}$; however, there have been no evaluations of patients' experiences of receiving naloxone through primary care.

\section{METHODS}

\section{Study Design}

We evaluated patients' experience in a naloxone co-prescribing program described in detail elsewhere. ${ }^{10}$ Six safety-net clinics, accepting only publicly insured or uninsured patients, initiated naloxone prescribing in 2013-2014. Selected clinics had lost patients to opioid overdose from 2010 to 2012 and maintained a pain management registry of patients receiving daily opioids for 3 or more months. Clinicians were advised to offer naloxone to patients on the pain management registry or who were otherwise at risk of experiencing or witnessing an overdose. Naloxone was generally prescribed in an off-label intranasal formulation because the only alternative at the time was a vial and syringe. Patients were taught to assemble and use the device and were given an educational brochure (Figure 1) and mucosal atomizer. Clinicians also educated patients' families, friends, or caregivers, if appropriate.

Clinics provided a list of patients prescribed naloxone who were aged 18 years and older, were prescribed longterm opioids, and spoke English, (because the interviewer was monolingual). Each list was randomized, and the first 10 patients from each list were contacted by telephone if patients were ineligible, unreachable, or refused participation, the next patient was contacted until we reached 10 interviews from each clinic. Interviews took place from October 2013 to October 2015, 6 to 9 months after each clinic began prescribing naloxone. Study activities were approved by the University of California San Francisco Committee on Human Research (CHR\#13-11168).

\section{Data Collection}

Interviews were conducted at the patients' clinics or in the research office. One interviewer trained in qualitative methods conducted all but 2 interviews, which were conducted by other study staff. All interviews were audio-recorded, with the exception of 4 cases when the participant declined recording. Patients verbally consented to the interview, were given an information form, and were compensated $\$ 25$. Study staff and Berkeley Transcription Services transcribed the interviews, after which the audio files were erased. Responses were entered into a secure database and analyzed using Stata 14 (StataCorp LP).

\section{Measures}

Interviews included 49 questions (Supplemental Appendix, available at http://www.annfammed.org/
content/14/5/431/suppl/DC1) addressing demographics, substance use, history of personal and witnessed overdose, overdose risk perception, feelings around and use of naloxone, related behavior changes, and attitudes about a future prescription. A Likert scale of 1 to 10 was used to gauge personal overdose risk perception, answers of 1 to 3 corresponded to low risk, 4 to 6 to moderate risk, and 7 to 10 to high risk.

We suspected the term overdose may not capture all opioid-poisoning events, thus we asked separately whether the patient had experienced an overdose and a bad reaction from opioid use. We analyzed reports of bad reactions consistent with overdose (eg, not breathing, unresponsive) and excluded reports inconsistent with overdose (eg, constipation, reduced libido).

\section{Data Analysis}

We used sentiment analysis to determine polarity around patients' reaction to being offered naloxone, coded positive, negative, or neutral. ${ }^{11}$ Three study staff independently reviewed 20 interviews and extracted emergent themes. The themes were compared and discrepancies were discussed until consensus was established, and a master codebook was generated for use by 2 staff to code all interviews. Positive responses included improved relationship with clinician, appreciation naloxone was offered, community benefits. Negative responses included offended by offer, believed it was undeserved, felt scared, and felt judged.

The same approach was used to identify polarity and thematic codes around behavior modification after receiving a naloxone prescription. Positive codes included improvements in opioid dosing, timing of opioid use, concomitant use of multiple substances, proper opioid storage, not using opioids alone, and increased knowledge around opioids and opioid overdose. No negative behavior changes were identified, thus no codes were created.

\section{RESULTS}

We interviewed 10 patients from each clinic $(\mathrm{N}=60)$, with interviews lasting on average 25 minutes (range $=11-70$ minutes). We had contacted 112 patients by telephone, $25 \%$ could not recall receiving naloxone, $9 \%$ declined the interview, $5 \%$ could not attend because of poor health, $3 \%$ no longer resided locally, and $1 \%$ each was deceased and incarcerated.

\section{Patient Characteristics}

Demographically the study sample was racially and ethnically diverse, most (55\%) were male and had a mean age of 59 years (Table 1). This study group compared favorably with the full population of 1,985 


\section{Figure 1. Opioid safety and how to use naloxone. A guide for patients and caregivers.}

\section{What is \\ an opioid \\ overdose?}

Opioids can cause bad reactions that make your breathing slow or even stop. This can happen if your body can't handle the opioids that you take that day.

\section{TO AVOID AN ACCIDENTAL} OPIOID OVERDOSE:

- Try not to mix your opioids with alcohol, benzodiazepines (Xanax, Ativan, Klonopin, Valium), or medicines that make you sleepy.

- Be extra careful if you miss or change doses, feel ill, or start new medications.

\section{Now that you have} naloxone...

Tell someone where it is and how to use it.

\section{How to identify an opioid overdose:}

Look for these common signs:

- The person won't wake up even if you shake them or say their name

Breathing slows or even stops

Lips and fingernails turn blue or gray

- Skin gets pale, clammy

\section{In case of overdose:}

(1) Call 911 and give naloxone

If no reaction in 3 minutes, give second naloxone dose

2 Do rescue breathing or chest compressions Follow 911 dispatcher instructions

\section{(3) After naloxone}

Stay with person for at least 3 hours or until help arrives

\section{Common opioids include:}

\begin{tabular}{l|l}
\hline GENERIC & BRAND NAME \\
\hline Hydrocodone & $\begin{array}{l}\text { Vicodin, Lorcet, Lortab, } \\
\text { Norco, Zohydro }\end{array}$ \\
\hline Oxycodone & $\begin{array}{l}\text { Percocet, OxyContin, } \\
\text { Roxicodone, Percodan }\end{array}$ \\
\hline Morphine & $\begin{array}{l}\text { MSContin, Kadian, } \\
\text { Embeda, Avinza }\end{array}$ \\
\hline Codeine & $\begin{array}{l}\text { Tylenol with Codeine, } \\
\text { TyCo, Tylenol \#3 }\end{array}$ \\
\hline Fentanyl & Duragesic \\
\hline Hydromorphone & Dilaudid \\
\hline Oxymorphone & Opana \\
\hline Meperidine & Demerol \\
\hline Methadone & Dolophine, Methadose \\
\hline Buprenorphine & $\begin{array}{l}\text { Suboxone, Subutex, } \\
\text { Zubsolv, Bunavail, } \\
\text { Butrans }\end{array}$ \\
\hline *Heroin is also an opioid. &
\end{tabular}

*Heroin is also an opioid.

For patient education, videos and additional materials, please visit www.prescribetoprevent.org

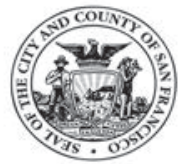

SAN FRANCISCO DEPARTMENT OF PUBLIC HEALTH

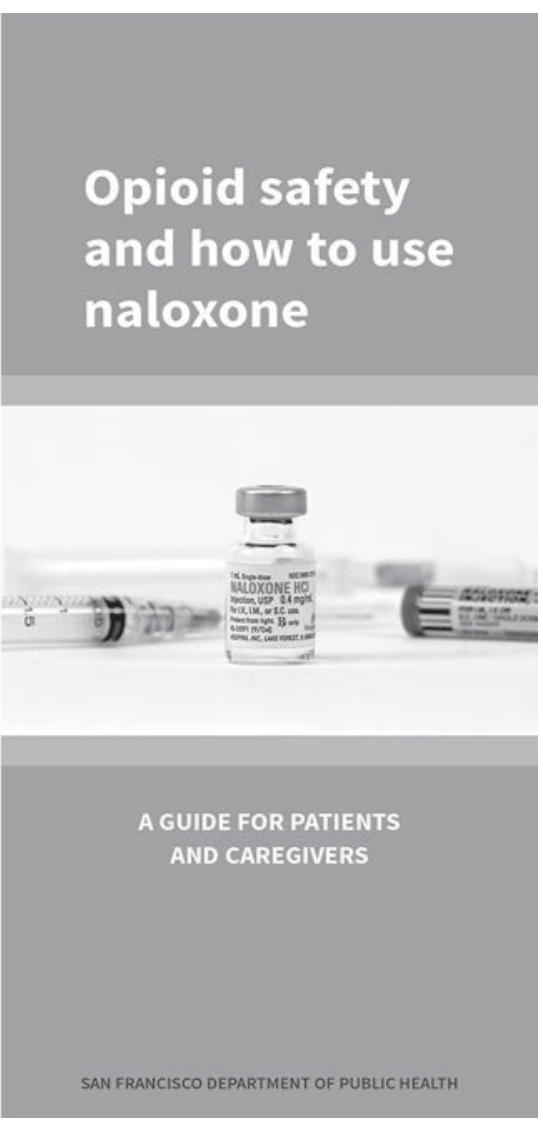

\section{How to give naloxone:}

There are 3 ways to give naloxone. Follow the instructions for the type you have.

\section{Nasal spray naloxone}

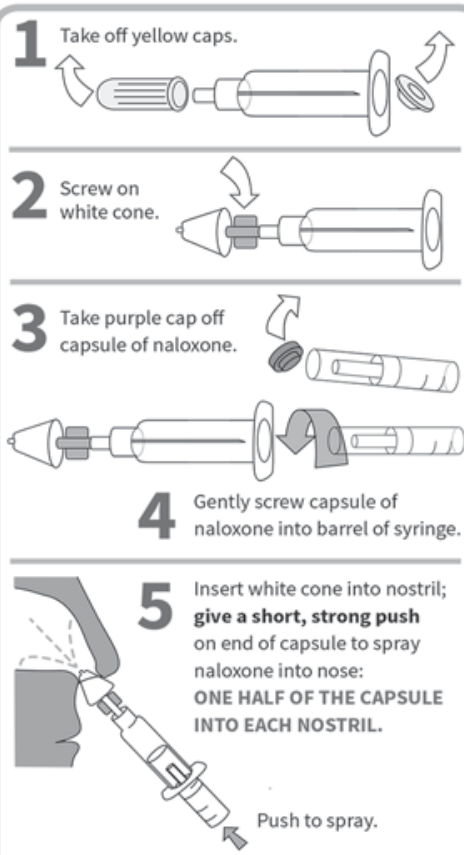

6 If no reaction in 3 minutes, give second dose.
Injectable naloxone

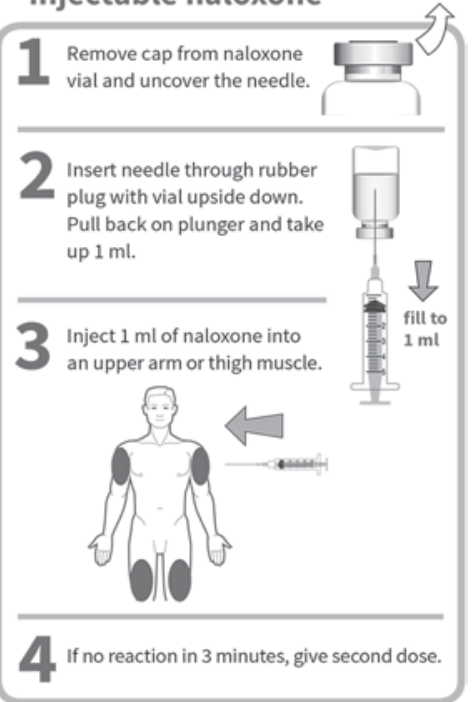

\section{Auto-injector}

The naloxone auto-injector is FDA approved for use by anyone in the community. It contains a speaker that provides instructions to inject naloxone into the outer thigh, through clothing if needed. 


\section{Table 1. Demographic and Behavioral Characteristics of Primary Care Patients Prescribed Naloxone $(\mathrm{N}=60)$}

\begin{tabular}{lc}
\hline Characteristic & No. (\%) \\
\hline Sex, male & $33(55)$ \\
Race/ethnicity & \\
White & $16(27)$ \\
African American & $33(55)$ \\
Hispanic & $5(8)$ \\
Mixed/other & $6(10)$ \\
Prescribed opioids for pain & $52(87)$ \\
Ever taken opioids not as prescribed & $32(53)$ \\
Opioids currently prescribed, mean (SD) & $1.3(0.8)$ \\
Previously received take-home naloxone & $6(10)$ \\
Previously had heard of naloxone $(n=52)$ & $21(40)$ \\
Naloxone ever used on participant $(n=22)$ & $6(27)$ \\
History of overdose/bad reaction & $22(37)$ \\
Overdose & $12(20)$ \\
Bad reaction & $10(17)$ \\
Ever witnessed an opioid overdose & $32(53)$ \\
Perceived personal risk of overdose $(n=47)$ & \\
Low $(<3)$ & $36(77)$ \\
Moderate (3-6) & $10(21)$ \\
High (>6) & $1(2)$ \\
\hline
\end{tabular}

patients prescribed long-term opioids (31\% white, $48 \%$ African American, 13\% Latino, and $8 \% \mathrm{mixed} /$ other race, $59 \%$ male with a mean age of 57 years). Nearly all patients reported being prescribed opioids for pain. Most patients had taken opioids not as prescribed and had witnessed an overdose. More than one-third had experienced at least 1 opioid-poisoning event ${ }_{i} 45 \%$ of which were reported as a bad reaction. For example, the following patient who reported using medications only as prescribed, had no history of illicit substance use, and denied any history of overdose reported reactions consistent with overdose:

Interviewer: How many times would you say you've had these bouts of delirium, or you've stopped breathing because of opioids?

Patient: Ever? Eight to 10 times.

Interviewer: And how many times has [naloxone] been used on you?

Patient: Oh, boy. That would be really hard to answer. I'd say somewhere in the neighborhood of 12 to 15 times.

Interviewer: So, around 12 to 15 times someone has given you [naloxone] because you've stopped breathing because of opioids?

Patient: Yes. Medical staff each time. Because of the opioids, I've stopped breathing.
Table 2. Responses to Prescribed Naloxone Among Primary Care Patients $(\mathrm{N}=60)$

\begin{tabular}{lc}
\hline Response & No. (\%) \\
\hline Attempted to fill naloxone prescription & $56(93)$ \\
Able to fill naloxone prescription $(n=56)$ & $49(88)$ \\
Naloxone prescription from study used on participant & $3(5)$ \\
Site of storage for naloxone $(n=48)$ & \\
Store at home & $39(81)$ \\
Carry with me & $6(13)$ \\
Unsure of location/lost & $3(6)$ \\
Person(s) trained by participant to use naloxone & \\
(n= 49) & \\
Family & $18(37)$ \\
Roommate & $12(24)$ \\
Friend & $11(22)$ \\
Partner & $8(16)$ \\
Neighbor & $5(10)$ \\
Housing staff & $5(10)$ \\
Nobody & $15(31)$ \\
Participant confidence in ability to use naloxone & \\
(n= 49) & \\
Not at all confident & $2(4)$ \\
A little confident & \\
Somewhat confident & $5(10)$ \\
Very confident & $13(26)$ \\
Participant confident person(s) they trained could & $29(59)$ \\
use naloxone $(n=34)$ & \\
Not at all confident & \\
A little confident & $3(9)$ \\
Somewhat confident & $1(3)$ \\
Very confident & $9(26)$ \\
& \\
\hline
\end{tabular}

Interviewer: Over what period of time?

Patient: Over 1 year.

Of the patients who had ever experienced an overdose or bad reaction, $27 \%$ reported having naloxone used on them, 3 reported the naloxone they were prescribed during the intervention had been used on them. Three-quarters of patients believed they were at low risk of overdose, including more than one-half the patients who experienced an overdose and 2 of 3 patients who were administered their prescribed naloxone (Tables 1 and 2).

\section{Naloxone Acceptability}

Ninety percent of patients had never previously received naloxone, and $60 \%$ had never heard of it before the intervention; $82 \%$ successfully filled the prescription. Most trained someone to use naloxone and were confident that person could administer it (Table 2).

Nearly all patients wanted a future naloxone prescription and believed it should be prescribed to at least some patients being prescribed opioids. Threequarters said naloxone increased their sense of security. 
One patient stated:

I thought [naloxone] was a wonderful idea. ... I have been on a reasonably high dose for many years and have never overdosed, but there have been at least 1 or 2 times where I've [said] "Oh, wait, I just took a pill 20 minutes ago and I just took another...oops!" It can happen to anybody.

Another patient suggested benefits of having naloxone in the home:

I think if any opioids prescribed at all that they definitely should make the patient get [naloxone] cause it's very useful especially for us with kids.

Most patients noted positive responses to a naloxone prescription offer, such as, "I felt like [my doctor] really

\section{Table 3. Reactions to and Perceptions of Naloxone Prescription Among Primary Care Patients $(\mathrm{N}=60)$}

\begin{tabular}{|c|c|}
\hline Perception and Reaction & No. (\%) \\
\hline \multicolumn{2}{|l|}{ Reaction to naloxone prescription offer } \\
\hline Positive & $34(57)$ \\
\hline Negative & $13(22)$ \\
\hline Neutral & $13(22)$ \\
\hline \multicolumn{2}{|l|}{$\begin{array}{l}\text { Reasons for positive reaction to naloxone prescription } \\
\text { offer }(n=34)\end{array}$} \\
\hline Benefits the community & $18(53)$ \\
\hline Appreciated it was offered & $14(41)$ \\
\hline Improved relationship with provider & $10(29)$ \\
\hline \multicolumn{2}{|l|}{$\begin{array}{l}\text { Reasons for negative reaction to naloxone prescription } \\
\text { offer }(n=13)\end{array}$} \\
\hline Prescription was undeserved & $10(77)$ \\
\hline Judged by clinician & $9(69)$ \\
\hline Scared & $8(61)$ \\
\hline Offended by the prescription & $3(23)$ \\
\hline \multicolumn{2}{|l|}{$\begin{array}{l}\text { Opioid-related behavior modification since receiving } \\
\text { naloxone }\end{array}$} \\
\hline Positive & $22(37)$ \\
\hline Neutral & $38(63)$ \\
\hline Negative & $0(0)$ \\
\hline \multicolumn{2}{|l|}{ Type of positive behavior modification $(n=8)$} \\
\hline Improved dosing & $7(88)$ \\
\hline Improved timing & $7(88)$ \\
\hline Improved knowledge around opioids and overdose & $5(63)$ \\
\hline Decrease in polysubstance use & $1(12)$ \\
\hline Decrease in using alone & $1(12)$ \\
\hline \multicolumn{2}{|l|}{$\begin{array}{l}\text { Would want naloxone prescription in the future } \\
(n=59)\end{array}$} \\
\hline Yes & $56(95)$ \\
\hline No & $1(2)$ \\
\hline Do not know & $2(3)$ \\
\hline \multicolumn{2}{|l|}{$\begin{array}{l}\text { Naloxone should be available to patients prescribed } \\
\text { opioids for pain }(n=59)\end{array}$} \\
\hline Yes, all & $47(80)$ \\
\hline Yes, some & $10(17)$ \\
\hline No & $0(0)$ \\
\hline Do not know & $2(3)$ \\
\hline
\end{tabular}

cared about me," and, "If I'm gonna stop breathing, I'd like to have [naloxone] available to me at all times." All but 1 of the $22 \%$ of patients with a negative reaction wanted a future naloxone prescription (Table 3 ).

\section{Behavior Change}

More than one-third of patients indicated positive behavior change after receiving naloxone, and none indicated negative behavior change. Eight patients articulated specific changes, most commonly safer dosing (88\%), safer timing (88\%), and increased knowledge around opioids and overdose (62\%). One patient explained: "I've probably been a little more cautious. Just being careful to take the right amount, count the hours...just thinking more cautiously about dosing." (Table 3).

\section{DISCUSSION}

We found a naloxone prescription to be acceptable to primary care patients who are prescribed opioids. Most patients responded positively to being offered naloxone, and among those with a negative reaction, all accepted the offer, and nearly all believed naloxone was appropriate for patients prescribed opioids. Since this project was initiated, the Food and Drug Administration has approved 2 naloxone products designed for layperson administration.

Most patients had neither heard of nor received naloxone before this intervention, suggesting that primary care prescribing reaches a population distinct from community distribution, even in a city with robust naloxone programming. ${ }^{12}$ Furthermore, although many patients had previously overdosed, and some were reversed during the intervention, perceived risk was low. One element of low perceived risk may be related to the term overdose, which implies consuming large amounts of opioids and disregards contextual and biologic factors that increase overdose risk without overconsumption. ${ }^{1,13-17}$

Finally, several patients reported positive behavior changes after receiving naloxone, suggesting that the reduction in overdoses found at Fort Bragg ${ }^{8}$ could be related to a behavioral impact of naloxone prescribing. Future studies should investigate strategies to maximize these potential effects and integrate naloxone prescribing with broader opioid stewardship efforts, including ensuring safe opioid prescribing and access to appropriate medical treatment of opioid use disorders, such as methadone and buprenorphine maintenance therapy.

Our study has generalizability limitations. The sample was limited to English-speaking patients because of staff language limitations. Patients agree- 
ing to be interviewed may not represent all patients; clinicians queried were able to identify only 1 patient who refused naloxone and requested we not contact that patient. Lastly, our sample had a high rate of nonmedical opioid use.

Prescribing naloxone appears to be acceptable among safety-net primary care patients prescribed long-term opioids, primary care clinicians may reach a population not served by community distribution, and prescriptions for naloxone may help reduce the morbidity and mortality of opioid poisoning. Although naloxone is neither a replacement nor an alternative to opioid stewardship efforts and provision of appropriate treatment for opioid use disorder, providing naloxone may be associated with beneficial behavior changes, a critical subject for future research. Finally, improved terminology is needed to describe opioid poisonings, as overdose may not reflect patients' perceptions of relevant events.

To read or post commentaries in response to this article, see it online at http://www.annfammed.org/content/14/5/431.

Key words: naloxone; opioid overdose; clinic-based prescribing

Submitted March 16, 2016; submitted, revised, May 4, 2016; accepted May 25, 2016.

Funding support: This study was supported the National Institutes of Health grant R21DA036776.

Disclaimer: The findings and conclusions in this report are those of the authors and do not necessarily represent the views of the San Francisco Department of Public Health.

Acknowledgments: Authors would like to thank the site leads at each clinic_Barbara Wismer, Diana Coffa, Jan Gurley, and Keith Seidel-and the clinical pharmacist Michelle Geier for participation in the coordination of this project, and Sarah Brennan for participation in the data analysis of this project.

Supplementary materials: Available at http://www.AnnFamMed. org/content/14/5/431/suppl/DC1/.

\section{References}

1. Rudd RA, Aleshire N, Zibbell JE, Gladden RM. Increases in Drug and Opioid Overdose Deaths-United States, 2000-2014. MMWR Morb Mortal Wkly Rep. 2016;64(50-51):1378-1382. http://www.cdc. gov/mmwr/preview/mmwrhtml/mm6450a3.htm. Accessed Feb 25, 2016.
2. Walley AY, Xuan Z, Hackman HH, et al. Opioid overdose rates and implementation of overdose education and nasal naloxone distribution in Massachusetts: interrupted time series analysis. BMJ. 2013;346:f174. http://www.pubmedcentral.nih.gov/articlerender.fcg i? artid $=4688551$ Etool = pmcentrez\&rendertype = abstract. Accessed Apr 21, 2016.

3. Bird SM, McAuley A, Perry S, Hunter C. Effectiveness of Scotland's National Naloxone Programme for reducing opioid-related deaths: a before (2006-10) versus after (2011-13) comparison. Addiction. 2016;111(5):883-891.

4. American Medical Association. Task force to reduce prescription opioid abuse. http://www.ama-assn.org/ama/pub/advocacy/topics/ combating-prescription-drug-abuse-diversion.page? Accessed Jan 16, 2016.

5. Medical Board of California. Guidelines for Prescribing Controlled Substances for Pain. http://www.mbc.ca.gov/licensees/prescribing/ pain_guidelines.pdf. Published Nov 2014. Accessed Nov 4, 2015.

6. The Centers for Disease Control and Prevention. Guidelines for prescribing controlled substances for pain. http://www.cdc.gov/drugoverdose/index.html. Published 2016. Accessed Mar 15, 2016.

7. Albert S, Brason FW II, Sanford CK, Dasgupta N, Graham J, Lovette B. Project Lazarus: community-based overdose prevention in rural North Carolina. Pain Med. 2011;12(Suppl 2):S77-S85.

8. Bartoszek M. Role of Naloxone in Opioid overdose fatality prevention. 2012. http://www.fda.gov/Drugs/NewsEvents/ucm277119.htm. Published Apr 2012. Accessed Nov 4, 2015.

9. Binswanger IA, Koester S, Mueller SR, Gardner EM, Goddard K, Glanz JM. Overdose education and naloxone for patients prescribed opioids in primary care: a qualitative study of primary care staff. J Gen Intern Med. 2015;30(12):1837-1844.

10. Coffin PO, Behar E, Rowe C, et al. Non-randomized intervention study of naloxone co-prescription for primary care patients on longterm opioid therapy for pain. Ann Intern Med. 2016;165(4):245-252.

11. Pang B, Lee L. Opinion mining and sentiment analysis. http://www. cs.cornell.edu/home/llee/omsa/omsa.pdf. Published 2008. Accessed Apr 21, 2016.

12. Enteen L, Bauer J, McLean R, et al. Overdose prevention and naloxone prescription for opioid users in San Francisco. J Urban Health. 2010;87(6):931-941.

13. Coffin PO, Tracy M, Bucciarelli A, Ompad D, Vlahov D, Galea S. Identifying injection drug users at risk of nonfatal overdose. Acad Emerg Med. 2007;14(7):616-623.

14. Binswanger IA, Blatchford PJ, Mueller SR, Stern MF. Mortality after prison release: opioid overdose and other causes of death, risk factors, and time trends from 1999 to 2009. Ann Intern Med. 2013; 159(9):592-600.

15. Angst MS, Lazzeroni LC, Phillips NG, et al. Aversive and reinforcing opioid effects: a pharmacogenomic twin study. Anesthesiology. 2012;117(1):22-37.

16. Green TC, McGowan SK, Yokell MA, Pouget ER, Rich JD. HIV infection and risk of overdose: a systematic review and meta-analysis. AIDS. 2012;26(4):403-417.

17. Webster LR, Cochella S, Dasgupta N, et al. An analysis of the root causes for opioid-related overdose deaths in the United States. Pain Med. 2011;12(Suppl 2):S26-S35. 